David Christopher (Orcid ID: 0000-0001-8504-2354)

Owen Andrew (Orcid ID: 0000-0002-9819-7651)

\title{
Dose Prediction for Repurposing Nitazoxanide in SARS-CoV-2 Treatment or
}

\section{Chemoprophylaxis}

Rajith K.R. Rajoli ${ }^{1}$, Henry Pertinez ${ }^{1}$, Usman Arshad ${ }^{1}$, Helen Box ${ }^{1}$, Lee Tatham ${ }^{1}$, Paul Curley ${ }^{1}$, Megan Neary ${ }^{1}$, Joanne Sharp ${ }^{1}$, Neill J. Liptrott ${ }^{1}$, Anthony Valentijn ${ }^{1}$, Christopher David ${ }^{1}$, Steven P. Rannard ${ }^{2}$, Ghaith Aljayyoussi ${ }^{3}$, Shaun H. Pennington ${ }^{3}$, Andrew Hill ${ }^{1}$, Marta Boffito ${ }^{4,5}$, Steve A. Ward ${ }^{3}$, Saye H. Khoo ${ }^{1}$, Patrick G. Bray ${ }^{6}$, Paul M. O'Neill², W. David Hong' ${ }^{2}$, Giancarlo Biagini ${ }^{3}$, Andrew Owen ${ }^{1}$.

${ }^{1}$ Department of Molecular and Clinical Pharmacology, Materials Innovation Factory, University of Liverpool, Liverpool, L7 3NY, UK

${ }^{2}$ Department of Chemistry, University of Liverpool, Liverpool, L69 3BX, UK

${ }^{3}$ Centre for Drugs and Diagnostics, and Department of Tropical Disease Biology, Liverpool School of Tropical Medicine, Liverpool L3 5QA, UK

${ }^{4}$ Chelsea and Westminster NHS Foundation Trust and St Stephen's AIDS Trust 4th Floor, Chelsea and Westminster Hospital, 369 Fulham Road, London, SW10 9NH, UK

5 Jefferiss Research Trust Laboratories, Department of Medicine, Imperial College, London, W2 1PG, UK

${ }^{6}$ Pat Bray Electrical, 260D Orrell Road, Orrell, Wigan, WN5 8QZ, UK

\section{Author for correspondence:}

Professor Andrew Owen

Department of Molecular and Clinical Pharmacology

Materials Innovation Factory

University of Liverpool

51 Oxford Street,

Liverpool L7 3NY

United Kingdom

Email - aowen@liverpool.ac.uk

Phone - +44 (0)151 7957129

Key words: COVID-19, SARS-CoV-2, Coronavirus, Pharmacokinetics, Lung

Figure count - 3

Table count -3

\section{Conflicts of interest statement}

AO and SPR are Directors of Tandem Nano Ltd. AO has received research funding from ViiV, Merck, Janssen and consultancy from Gilead, ViiV and Merck not related to the current paper. PON is currently engaged in a collaboration with Romark LLC but this interaction did not

This article has been accepted for publication and undergone full peer review but has not been through the copyediting, typesetting, pagination and proofreading process which may lead to differences between this version and the Version of Record. Please cite this article as doi: $10.1111 /$ bcp. 14619 
influence the prioritisation or conclusions in the current manuscript. No other conflicts are declared by the authors.

\section{Funding}

The authors received no funding for the current work. AO acknowledges research funding from EPSRC (EP/R024804/1; EP/S012265/1), NIH (R01AI134091; R24AI118397), European Commission (761104) and Unitaid (project LONGEVITY). GAB acknowledges support from the Medical Research Council (MR/S00467X/1). GA acknowledges funding from the MRC Skills Development Fellowship.

\section{Principal investigator statement}

The authors confirm that the PI for this paper is Andrew Owen and the study informs dosing optimisation using a mathematical model without any involvement of actual patients.

Running head - Nitazoxanide for SARS-CoV-2 therapy

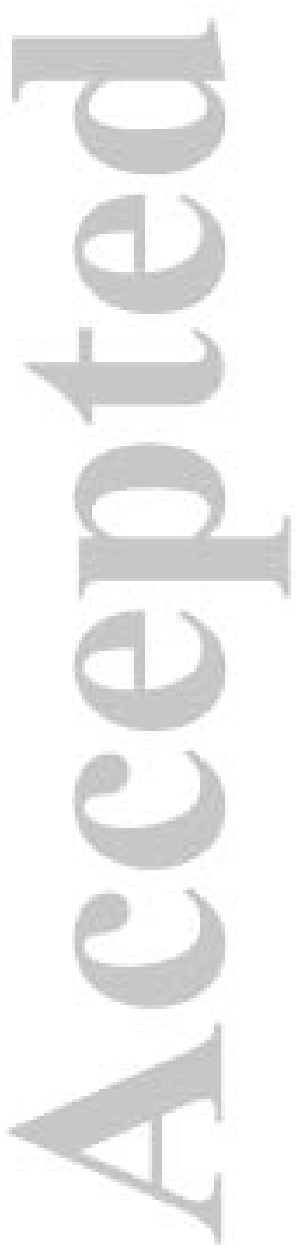




\section{Abstract}

Background: Severe acute respiratory syndrome coronavirus 2 (SARS-CoV-2) has been declared a global pandemic and urgent treatment and prevention strategies are needed. Nitazoxanide, an anthelmintic drug has been shown to exhibit in vitro activity against SARSCoV-2. The present study used physiologically-based pharmacokinetic (PBPK) modelling to inform optimal doses of nitazoxanide capable of maintaining plasma and lung tizoxanide exposures above the reported SARS-CoV-2 EC90.

Methods: A whole-body PBPK model was validated against available pharmacokinetic data for healthy individuals receiving single and multiple doses between 500-4000 mg with and without food. The validated model was used to predict doses expected to maintain tizoxanide plasma and lung concentrations above the $\mathrm{EC}_{90}$ in $>90 \%$ of the simulated population. PopDes was used to estimate an optimal sparse sampling strategy for future clinical trials.

Results: The PBPK model was successfully validated against the reported human pharmacokinetics. The model predicted optimal doses of $1200 \mathrm{mg}$ QID, $1600 \mathrm{mg}$ TID, 2900 mg BID in the fasted state and 700 mg QID, 900 mg TID and 1400 mg BID when given with food. For BID regimens an optimal sparse sampling strategy of $0.25,1,3$ and $12 \mathrm{~h}$ post dose was estimated.

Conclusion: The PBPK model predicted tizoxanide concentrations within doses of nitazoxanide already given to humans previously. The reported dosing strategies provide a rational basis for design of clinical trials with nitazoxanide for the treatment or prevention of SARS-CoV-2 infection. A concordant higher dose of nitazoxanide is now planned for investigation in the seamless phase I/Ila AGILE trial (www.agiletrial.net). 


\section{Introduction}

COVID-19 is a respiratory illness caused by severe acute respiratory syndrome coronavirus 2

(SARS-CoV-2) with noticeable symptoms such as fever, dry cough, and difficulty in breathing

[1]. There are currently no effective treatment or prevention options and it has become a global health problem with more than 3.1 million cases and over 217,000 deaths as of $29^{\text {th }}$ April 2020 [2]. Urgent strategies are required to manage the pandemic and the repurposing of already approved medicines is likely to bring options forward more quickly than full development of potent and specific antivirals. Antiviral drugs may have application prior to or during early infection, but may be secondary to immunological interventions in later stages of severe disease [3].

Although new chemical entities are likely to have high potency and specificity for SARS-CoV2 , full development is time consuming, costly and attrition in drug development is high [4, 5]. Drug repurposing, where existing or investigational drugs could be used outside the scope of their original indication may present a rapid alternative to new drug development. Several examples of successful repurposing exist, including the use of the anti-angiogenic drug thalidomide for cancer, the use of mifepristone for Cushing's disease after initially being approved for termination of early pregnancy, and the repurposing of sildenafil from angina to erectile disfunction $[6,7]$. It should be noted though, that drug repurposing is considerably faster when the approved dose is successfully repurposed, with additional complexity in clinical development when higher doses are required. 
SARS-CoV-2 targets the angiotensin-converting enzyme 2 (ACE2) receptors that are present in high density on the outer surface of lung cells [1]. Lungs are the primary site of SARS-CoV-

2 replication and infection is usually initiated in the upper respiratory tract [8]. Symptoms that result in neurological, renal and hepatic dysfunction are also emerging due to the expression of ACE2 receptors in these organs [9-12]. Therefore, therapeutic concentrations of antiviral drugs are likely to be needed in the upper airways for treatment and prevention of infection, but sufficient concentrations are also likely to be required systemically for therapy to target the virus in other organs and tissues.

The scale at which antiviral activity of existing medicines is being studied for potential repurposing against SARS-CoV-2 is unprecedented [13]. The authors recently reported an analysis which benchmarked reported in vitro activity of tested drugs against previously published pharmacokinetic exposures achievable with their licenced doses [14]. Importantly, this analysis demonstrated that the majority of drugs that have been studied for anti-SARS-CoV-2 activity are unlikely to achieve the necessary concentrations in the plasma after administration of their approved doses. While this analysis is highly influenced by the drugs selected for analysis to date and highly sensitive to the accuracy of the reported antiviral activity data, a number of candidate agents were identified with plasma exposures above the reported $\mathrm{EC}_{50} / \mathrm{EC}_{90}$ against SARS-CoV-2.

One such drug, nitazoxanide, is a thiazolide antiparasitic medicine used for the treatment of cryptosporidiosis and giardiasis that cause diarrhoea $[15,16]$, and also has reported activity against anaerobic bacteria, protozoa and other viruses [17]. Several reports have confirmed the activity of nitazoxanide against SARS-CoV-2 in different cell types [18-21]. Importantly, 
rapid deacetylation of nitazoxanide in blood means that the major systemic species of the drug in vivo is tizoxanide, which has been shown to exhibit similar in vitro inhibitory activity to nitazoxanide for rotaviruses [22], hepatitis B and C viruses [23, 24], other coronaviruses, noroviruses [25],influenza viruses and SARS-CoV-2 [20, 26-28]. As another respiratory virus, previous work on influenza may be useful to gain insight into the expected impact of nitazoxanide for SARS-CoV-2. Accordingly, the drug has been shown to selectively block the maturation of the influenza haemagglutinin glycoprotein at the post-translational stage [27, 29] and a previous phase $2 b / 3$ trial demonstrated a reduction in symptoms and viral shedding at a dose of $600 \mathrm{mg}$ BID compared to placebo in patients with uncomplicated influenza [30]. Other potential benefits of nitazoxanide in COVID-19 may derive from its impact upon the innate immune response that potentiates the production of type 1 interferons [31, 32] and bronchodilation of the airways through inhibition of TMEM16A ion channels [33]. As of $9^{\text {th }}$ August 2020, a total of 19 trials are listed as either planned or recruiting on clinicaltrials.gov but all of these studies are focusing upon doses of $\leq 1000 \mathrm{mg}$ BID nitazoxanide either alone or in combination with other agents [34]. However, there are currently no data within the public domain to support these doses for COVID-19.

Nitazoxanide is relatively safe in humans and a review of the safety and minimum pricing was recently published [35]. Plasma concentrations of tizoxanide have demonstrated dose proportionality, but administration in the fed state increases the plasma exposure [36]. Thus, the drug is recommended for administration with food.

The prerequisites for successful development of antiviral drugs for SARS-CoV-2 have yet to be elucidated and gaps in knowledge exist in terms of the exposure-response relationship. However, the lung has emerged as a clear site of primary infection, and pulmonary co- 
morbidities are a key driver of mortality in the sickest patients [37-39]. Therefore, in treatment of early disease at least it seems likely that successful antiviral regimens will require drugs to penetrate into the lung at sufficient concentrations to exert their activity. Using HIV as a paradigm for successful chemoprophylactic approaches, antiviral drugs also require penetration into key sites of transmission such as the anal and vaginal mucosa [40-

42]. Therefore, the authors hypothesise that drugs achieving concentrations in lung that exceed those needed for activity will underpin successful antiviral development.

Physiologically based pharmacokinetic (PBPK) modelling is a computational tool that integrates human physiology and drug disposition kinetics using mathematical equations to inform the pharmacokinetic exposure using in vitro and drug physicochemical data [43]. Recently, several international groups have called for a more robust integration of clinical pharmacology principles into COVID-19 drug development [44, 45]. Accordingly, the aim of this study was to validate a PBPK model for tizoxanide following administration of nitazoxanide. Once validated, this model was first used to assess the plasma and lung exposures estimated to be achieved during a previous trial for uncomplicated influenza. Next, different nitazoxanide doses and schedules were simulated to identify those expected to provide tizoxanide plasma and lung trough concentrations $\left(C_{\text {trough }}\right)$ above the reported nitazoxanide SARS-CoV-2 $\mathrm{EC}_{90}$ in the majority (>90\%) of patients.

\section{Methods}

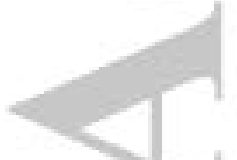

A previously published whole-body PBPK model consisting of compartments to represent select organs and tissues developed in Simbiology (MATLAB R2019a, MathWorks Inc., 
Natick, MA, USA) was used in this study $[46,47]$. Nitazoxanide physiochemical and drugspecific parameters used in the PBPK model were obtained from literature sources as outlined in Table 1. The PBPK model was assumed to be blood-flow limited, with instant and uniform distribution in each tissue or organ and no reabsorption from the large intestine. Since the data are computer generated, no ethics approval was required for this study.

\section{Model development}

One hundred virtual healthy adults (50\% women, aged 20-60 years between $40-120 \mathrm{~kg}$ ) were simulated. The required duration for successful SARS-CoV-2 antiviral activity has not yet been robustly elucidated but for clarity in presentation, the simulations were conducted over 5 days of dosing. It should be noted that similar exposures would be expected beyond this once the drug has reached steady-state pharmacokinetics. Patient demographics such as weight, $\mathrm{BMI}$ and height were obtained from CDC charts [48]. Organ weight/volumes and blood flow rates in humans were obtained from published literature sources $[49,50]$. Transit from the stomach and small intestine was divided into seven compartments to capture effective absorption kinetics as previously described [51]. Tissue to plasma partition ratio of drug and drug disposition across various tissues and organs were described using published mathematical equations [52-54]. Effective permeability $\left(P_{\text {eff }}\right)$ in humans was scaled from apparent permeability ( $\mathrm{P}_{\text {app }}$ ) in HT29-19A cells (due to lack of available data, it was assumed the same in Caco-2 cells) using the following equations to compute the rate of absorption $\left(K_{a}\right.$ in $\left.h^{-1}\right)$ from the small intestine.

$$
\log _{10} P_{\text {eff }}=0.6836 \times \log _{10} P_{\text {app }}-0.5579
$$


$K_{a}=\frac{2 \times P_{e f f} \times 60 \times 60}{r}$

\section{Model validation}

The PBPK model was validated against available clinical data in healthy individuals in the fed and fasted state for various single oral doses of nitazoxanide ranging from $500 \mathrm{mg}$ to 4000 $\mathrm{mg}[36,57]$, and for multiple dosing at $500 \mathrm{mg}$ and $1000 \mathrm{mg}$ BID with food. Nitazoxanide absorption was considered using the available apparent permeability data (shown in Table 1) and tizoxanide was assumed to form as soon as the drug reached systemic circulation as metabolic studies have shown it takes just 6 minutes for complete conversion into the active circulating metabolite, with no trace of nitazoxanide detected in plasma [58]. Therefore, tizoxanide parameters were used to define drug disposition. The elimination pathway of tizoxanide is not clear from the literature, therefore apparent clearance obtained from the literature was used as a first-order rate from the veinal compartment.

Due to the unavailability of transporter pathways, a fixed absorption rate computed from apparent permeability was considered in the model. The model was assumed to be validated if: 1) the absolute average fold error (AAFE) between the observed and the simulated plasma concentrations-time curve of tizoxanide was less than two; and 2) the simulated pharmacokinetic parameters-maximum concentration $\left(C_{\max }\right)$, area under the plasma concentration-time curve (AUC) and $C_{\text {trough }}$ (trough concentration at the end of the dosing interval) were less than 2 -fold from the mean observed values. 


\section{Model simulations}

The pharmacokinetics following administration of $600 \mathrm{mg}$ BID as reported in a previous phase $2 \mathrm{~b} / 3$ clinical trial of nitazoxanide in uncomplicated influenza [30] were first simulated and plotted relative to the average of previously reported influenza $\mathrm{EC}_{90 \mathrm{~S}}[59,60]$ for strains (as shown in Supplementary Table 1) included in the previous trials. This was done to assess the exposure relative to in vitro activity for an indication where clinical benefit was already demonstrated.

For potential SARS-CoV-2 applications, several oral dosing regimens were simulated for BID, TID or QID administration in the fasted state. Antiviral activity data from Wang et al. [18] were digitised using Web Plot Digitiser ${ }^{\circledast}$ software and used to calculate a nitazoxanide $\mathrm{EC}_{90}$ for SARS-CoV-2 of $4.64 \mu \mathrm{M}(1.43 \mathrm{mg} / \mathrm{L})$. Optimal doses were identified such that the concentration at $12 \mathrm{~h}$ post-first dose $\left(C_{12}\right)$ for BID, $8 \mathrm{~h}$ post-first dose $\left(C_{8}\right)$ for TID, or $6 \mathrm{~h}$ postfirst dose $\left(C_{6}\right)$ for QID administration were over the recalculated $E_{90}$ for nitazoxanide. Plasma and lung tizoxanide exposures at these doses and schedules are reported in addition to plasma-time curves. The doses were optimised using tizoxanide parameters and pharmacokinetics; however, the doses were reported for nitazoxanide.

\section{Optimal pharmacokinetic sampling}

Clinical trials should incorporate pharmacokinetic sampling to confirm tizoxanide plasma exposures, and further validate the predictions from the PBPK model. Optimal sparse pharmacokinetic timepoint selection (assuming four blood samples per patient, and 40 patients in the study) was made on the basis of the prior fed pharmacokinetic data of Stockis et al. [36, 57]. Tizoxanide plasma pharmacokinetic data in fed patients from Stockis 
et al. was fitted with an empirical one-compartment disposition model, with first-order absorption and absorption transit compartment, and the parameters from this fitting were used (with nominal \%CV interindividual variability in the pharmacokinetic parameters of 30\%) in the optimal design software PopDes (University of Manchester Version 4.0) to generate the suggested optimal sampling timepoints $[61,62]$.

\section{Nomenclature of Targets and Ligands}

Key protein targets and ligands in this article are hyperlinked to corresponding entries in http://www.guidetopharmacology.org, the common portal for data from the IUPHAR/BPS Guide to PHARMACOLOGY.

\section{Results}

\section{Model validation}

The PBPK model validation against various fasted oral doses is shown in Figure S1 and the validation against single and multiple doses in the fed state is shown in Figure S2. The corresponding pharmacokinetic parameters ( $A \cup C, C_{\max }$ and $C_{\text {trough }}$ ) are presented in Table 2 and 3. The AAFE values for the validated doses ranged between 1.01-1.55 for fasted state and between 1.1-1.58 for fed state indicating a close match between observed and simulated data. The ratio between the simulated and the observed pharmacokinetic parameters - AUC, $C_{\max }$ and $\mathrm{C}_{\text {trough }}$ - was between 0.81-1.54 (Table 2) for fasted state and between $0.67-2.15$ for fed state. The PBPK model simulated tizoxanide plasma concentrations were within acceptable ranges and therefore the PBPK model was assumed to be validated. 


\section{Model simulations}

Figure $1 \mathrm{a}$ and $1 \mathrm{~b}$ show the simulated plasma and lung exposures relative to the average influenza $\mathrm{EC}_{90}$ after administration of $600 \mathrm{mg}$ BID dose of nitazoxanide with food as reported in the previous phase $2 b / 3$ trial in uncomplicated influenza [30]. These simulations indicate that all patients were predicted to have plasma and lung tizoxanide $C_{\text {trough }}\left(C_{12}\right)$ concentrations below the average $\mathrm{EC}_{90}(8.4 \mathrm{mg} / \mathrm{L}$, Table S1) [60], but that $71 \%$ and $14 \%$ were predicted to have plasma and lung $C_{\max }$ concentrations, respectively, above the average $\mathrm{EC}_{90}$ for influenza, respectively.

Figure $2 \mathrm{a}$ and $2 \mathrm{~b}$ shows the prediction of trough concentrations in plasma and lung for the different simulated doses and schedules in healthy individuals for fasted and fed states, respectively. Doses and schedules estimated to provide plasma $C_{\text {trough }}$ concentrations over $1.43 \mathrm{mg} / \mathrm{L}$ for at least $50 \%$ of the simulated population were identified. However, lower doses in each schedule (i.e. $800 \mathrm{mg}$ QID, $1300 \mathrm{mg}$ TID and $1800 \mathrm{mg}$ BID in fasted state and $500 \mathrm{mg}$ QID, $700 \mathrm{mg}$ TID and $1100 \mathrm{mg}$ BID in fed state) were predicted to result in $>40 \%$ of the simulated population having lung $\mathrm{C}_{\text {trough }}$ below the SARS-CoV-2 EC 90 . Optimal doses for SARS-CoV-2 in the fasted state were predicted to be $1200 \mathrm{mg}$ QID, $1600 \mathrm{mg}$ TID and 2900 mg BID, and in the fed state were $700 \mathrm{mg}$ QID, $900 \mathrm{mg}$ TID and $1400 \mathrm{mg}$ BID. Figure 3 shows the plasma and lung concentrations for the optimal doses and schedules in fed state and Figure S3 shows the plasma concentration-time profile of optimal doses in fasted state. Tizoxanide concentrations in lung and plasma were predicted to reach steady state in $<48 \mathrm{~h}$, both in the fasted and fed state. 


\section{Optimal sparse sampling design}

Results from PopDes optimal design procedure indicate pharmacokinetic sampling timepoints at $0.25,1,3$ and $12 \mathrm{~h}$ post dose for BID regimens, and 0.25, 1, 2 and $8 \mathrm{~h}$ post dose for TID regimens.

\section{Discussion}

Treatment of SARS-CoV-2 has become a major global healthcare challenge with no welldefined therapeutic agents to either treat or prevent the spread of the infection. Short-term treatment options are urgently required but many ongoing trials are not based upon a rational selection of candidates in the context of safe achievable drug exposures. In the absence of a vaccine, there is also an urgent need for chemo preventative strategies to protect those at high risk such as healthcare staff, key workers and household contacts who are more vulnerable to infection. Nitazoxanide has emerged as a potential candidate for repurposing for COVID-19. The PBPK model presented herein was validated with an acceptable variation in AAFE and simulated/observed ratio (close to 1), which provides confidence in the presented predictions. The present study aimed to define the optimal doses and schedules for maintaining tizoxanide plasma and lung concentrations above the reported nitazoxanide $\mathrm{EC}_{90}$ for the duration of the dosing interval.

Nitazoxanide was assessed in a double-blind, randomised, placebo-controlled, phase $2 b / 3$ trial (NCT01227421) of uncomplicated influenza in 74 primary care clinics in the USA between 27 December 2010 and 30 April 2011 [63]. The median duration of symptoms for patients receiving placebo was $117 \mathrm{~h}$ compared with $96 \mathrm{~h}$ in patients receiving $600 \mathrm{mg}$ BID nitazoxanide with food. Importantly, virus titre in nasopharyngeal swabs in 39 patients receiving nitazoxanide $600 \mathrm{mg}$ BID was also lower than in 41 patients receiving placebo. The 
average of reported tizoxanide $\mathrm{EC}_{90}$ for influenza A and B [64] was calculated to be 8.4 $\mathrm{mg} / \mathrm{L}$, which is higher than the one reported $\mathrm{EC}_{90}$ for nitazoxanide against SARS-CoV-2 [18]. The PBPK model was used to simulate plasma and lung exposures after administration of $600 \mathrm{mg}$ BID for 5 days, and while only plasma $C_{\max }$ exceeded the average influenza $\mathrm{EC}_{90}$ in the majority of patients, the $\mathrm{C}_{\text {trough }}$ values did not. The modelling data suggest that the moderate effects of nitazoxanide seen in influenza could be a function of underdosing. Although influenza and SARS-CoV-2 both elicit pulmonary disease, it should be noted that the viruses are quite dissimilar. However, taken collectively when benchmarked against the in vitro activities of both viruses, these data are encouraging for the application of nitazoxanide in COVID-19. Moreover, these simulations indicate that higher doses may be optimal for maximal suppression of other pulmonary viruses.

In some cases, food intake may be difficult in patients with COVID-19 so drugs that can be given without regard for food may be preferred. However, the presented predictions indicate that optimal plasma and lung exposures would require $1200 \mathrm{mg}$ QID, $1600 \mathrm{mg}$ TID or $2900 \mathrm{mg}$ BID in the fasted state. Conversely, the PBPK models predict that doses of 700 mg QID, 900 mg TID or 1400 mg BID with food provide tizoxanide concentrations in plasma and lung above the $\mathrm{EC}_{90}$ value for nitazoxanide for the entire dosing interval in at least $90 \%$ of the simulated population. Single doses up to $4000 \mathrm{mg}$ have been administered to humans previously [36] but the drug is usually administered at $500 \mathrm{mg}$ BID. The PBPK model simulations indicate a high BID dose of $1400 \mathrm{mg}$ (fed) and caution may be needed for gastrointestinal intolerance at this dose. The simulations indicate that lower TID and QID dosing regimens may also warrant investigation, and $900 \mathrm{mg}$ TID as well as $700 \mathrm{mg}$ QID (both with food) regimens are also predicted to provide optimal exposures for efficacy. 
Importantly, the overall daily dose was estimated to be comparable between the different optimal schedules and it is unclear whether splitting the dose will provide gastrointestinal benefits. For prevention application where individuals will need to adhere to regimens for longer durations, minimising the frequency of dosing is likely to provide adherence benefits. However, for short-term application in therapy, more frequent dosing may be more acceptable to minimise gastrointestinal intolerance.

Nitazoxanide mechanism of action for SARS-CoV-2 is currently unknown. However, for influenza it has been reported to involve interference with $\mathrm{N}$-glycosylation of haemagglutinin $[27,64,65]$. Since the SARS-CoV-2 spike protein is also heavily glycosylated [66] with similar cellular targets in the upper respiratory tract, a similar mechanism of action may be expected $[8,67]$. An ongoing trial in Mexico is being conducted with $500 \mathrm{mg}$ BID nitazoxanide with food [34] but these doses may not be completely optimal for virus suppression across the entire dosing interval.

This analysis provides a rational dose optimisation for nitazoxanide for treatment and prevention of COVID-19. However, there are some important limitations that must be considered. PBPK models can be useful in dose prediction but the quality of predictions is only as good as the quality of the available data on which they are based. Furthermore, the mechanism of action for nitazoxanide for other viruses has also been postulated to involve an indirect mechanism through amplification of the host innate immune response [68], and this would not have been captured in the in vitro antiviral activity that informed the target concentrations for this dose prediction. The simulated population used in this modelling consisted of healthy individuals up to 60 years old, but many patients requiring therapy may 
be older and have underlying comorbidities. To best knowledge, the impact of renal and hepatic impairment on pharmacokinetics of this drug have not been assessed and may impact the pharmacokinetics. Although the current PBPK model is validated against various single doses in the fasted state and few multiple doses when given with food, the model may predict with less accuracy for multiple doses due to the unavailability of clinical data for multiple dosing over $1000 \mathrm{mg}$. The unusual shape of the observed PK curve in Figure S1e ( $4000 \mathrm{mg}$, fasted state) and Figure S2d (3000 mg, fed state) may be an error in the sampling or due to the low number of individuals in the study and this cannot be captured using the PBPK model since the exact cause of this is unknown, but the AAFE values and the ratio between observed and simulated PK parameters is less than 2 which implies the model as validated. Also, the observed vs. simulated curve for preceding doses i.e. $3000 \mathrm{mg}$ in fasted state (Figure S1d) and $2000 \mathrm{mg}$ (Figure S2c) in fed state are on par and the informed optimal doses are below these doses ( $2900 \mathrm{mg}$, fasted and $1400 \mathrm{mg}$, fed) and therefore the predictions would not have any impact of deviations in this case. The presented models were validated using BID doses only, and confidence in the predictions for TID and QID doses may be lower. The clinical studies used for model validation were performed in a limited number of patients [36] and thus may underrepresent real inter-subject variability. Also, the disposition parameters (apparent clearance and rate of absorption) obtained for the PBPK model were from a fasted study of $500 \mathrm{mg}$ BID, and the parameters were adjusted to validate the tizoxanide model in the fed state, which may limit confidence in the model at higher doses. Only one manuscript has described the in vitro activity of nitazoxanide against SARS-CoV-2 [18] and no data are available for tizoxanide. Reported in vitro data may vary across laboratories and due to this the predicted optimal doses may change. However, the reported comparable activity of nitazoxanide and tizoxanide against a variety of other 
viruses (including other coronaviruses) does strengthen the rationale for investigating this drug for COVID-19 [22-24, 26, 27]. Recently, several international investigators with experience of protein binding and its application in successful therapy for other viruses initiated a discussion about protein binding to reach consensus on its correct interpretation for SARS-CoV-2 [69]. As an outcome of this consensus, care should be taken to neither overnor under-represent its consequences. Unfortunately, assessment of the consequences of protein binding needs to involve empirical determination as part of the in vitro methodology, and none of the reported $\mathrm{EC}_{90}$ values for influenza or SARS-CoV-2 were protein binding-adjusted [18]. Tizoxanide is known to be highly protein bound (>99\%) in plasma [70] butwhile this was used to estimate drug penetration into the lung, data were not available to correct the in vitro activity to make a robust assessment in relation to the free drug pharmacokinetics.

The doses estimated to be necessary to maintain active tizoxanide concentrations in plasma and lung are considerably higher than the approved dose (500 mg BID) or other multiple dose studies that have been published to date. However, single doses of up to $4000 \mathrm{mg}$ have been given safely to humans previously, and several of the authors recently reviewed the safety of nitazoxanide across the different doses at which it has been studied $[35,71]$. Nitazoxanide appears to be a remarkably safe drug but the major concerns are likely to relate to gastrointestinal safety. Accordingly, the doses proposed here will require a clinical development pathway that robustly addresses the safety. As a first step, Unitaid have recently agreed funding and an independent scientific advisory board has approved inclusion of high dose nitazoxanide in the seamless phase I/Ila AGILE platform trial (www.agiletrial.net), subject to successful relevant ethical and regulatory approvals. 
In summary, the developed PBPK model of nitazoxanide was successfully validated against clinical data and based on currently available data, optimal doses for COVID-19 were estimated to be $700 \mathrm{mg}$ QID, $900 \mathrm{mg}$ TID or $1400 \mathrm{mg}$ BID with food. Should nitazoxanide be progressed into clinical evaluation for treatment and prevention of COVID-19, it will be important to further evaluate the pharmacokinetics in these population groups. In treatment trials particularly, intensive pharmacokinetic sampling may be challenging. Therefore, an optimal sparse sampling strategy for BID, TID and QID dosing is also presented.

\section{Study Highlights}

\section{What is the current knowledge on the topic?}

COVID-19, an acute respiratory infection caused by SARS-CoV-2, has been declared as a pandemic by the World Health Organization. Several repurposed drugs are being evaluated but currently there are no robustly validated treatment or preventative medicines or regimens. Nitazoxanide has shown in vitro activity against SARS-CoV-2, influenza and several other animal and human RNA viruses.

\section{What question did this study address?}

The manuscript describes the pharmacokinetics of tizoxanide, the active metabolite of nitazoxanide using a physiologically based pharmacokinetic (PBPK) model. The validated PBPK model was used to estimate the optimal doses required for SARS-CoV-2 treatment or prevention such that $>90 \%$ of the simulated population would have tizoxanide concentrations in the plasma and lung above the reported $90 \%$ effective concentration ( $\left.E C_{90}\right)$ value of nitazoxanide for the entire dosing interval. 


\section{What does this study add to our knowledge?}

There are no reported studies that identify treatment regimens of nitazoxanide for SARSCoV-2 treatment or prevention. The current study provides support for alternative dosing regimens of nitazoxanide for SARS-CoV-2 treatment and prevention that exceeds antiviral $\mathrm{EC}_{90} \mathrm{~S}$ in key tissues and organs for the duration of the dosing interval.

\section{How might this change clinical pharmacology or translational science?}

Efficacy of nitazoxanide has been demonstrated for uncomplicated influenza and the presented predictions may help inform nitazoxanide dose selection for COVID-19 clinical trials.

\section{Acknowledgements}

The authors acknowledge Prof. David Back from the University of Liverpool for his advice and feedback on this manuscript. The authors also thank Articulate Science for publication support.

\section{Author Contributions}

All authors contributed intellectually to the work during the UK COVID19 lock-down and commented on multiple drafts of the manuscript. A.O. and R.R. designed the research. U.A., H.B., L.T., H.P. and A.O. performed the research. R.R. and H.P. analysed the data.

\section{Data availability}

The data presented in this study is available from the corresponding author upon request. 


\section{References}

1. Machhi, J., et al., The Natural History, Pathobiology, and Clinical Manifestations of SARS-CoV-2 Infections. Journal of Neuroimmune Pharmacology, 2020. 15(3): p. 359386.

2. Johns Hopkins University of Medicine. Coronavirus Resource Center. 2020 [cited 2020 17/04/2020]; Available from: https://coronavirus.jhu.edu/map.html.

3. Zhang, W., et al., The use of anti-inflammatory drugs in the treatment of people with severe coronavirus disease 2019 (COVID-19): The Perspectives of clinical immunologists from China. Clinical immunology (Orlando, Fla.), 2020. 214: p. 108393-108393.

4. Gns, H.S., et al., An update on Drug Repurposing: Re-written saga of the drug's fate. Biomedicine \& Pharmacotherapy, 2019. 110: p. 700-716.

5. Charlton, R.L., et al., Repurposing as a strategy for the discovery of new antileishmanials: the-state-of-the-art. Parasitology, 2018. 145(2): p. 219-236.

6. Telleria, C.M., Drug Repurposing for Cancer Therapy. Journal of cancer science \& therapy, 2012. 4(7): p. ix-xi.

7. Senanayake, S.L., Drug repurposing strategies for COVID-19. Future Drug Discovery, 2020. 2(2): p. null.

8. Shereen, M.A., et al., COVID-19 infection: Origin, transmission, and characteristics of human coronaviruses. Journal of Advanced Research, 2020. 24: p. 91-98.

9. Adhikari, S.P., et al., Epidemiology, causes, clinical manifestation and diagnosis, prevention and control of coronavirus disease (COVID-19) during the early outbreak period: a scoping review. Infectious Diseases of Poverty, 2020. 9(1): p. 29.

10. Zhu, N., et al., A Novel Coronavirus from Patients with Pneumonia in China, 2019. New England Journal of Medicine, 2020. 382(8): p. 727-733.

11. $\mathrm{Xu}, \mathrm{H}$., et al., High expression of ACE2 receptor of 2019-nCoV on the epithelial cells of oral mucosa. International Journal of Oral Science, 2020. 12(1): p. 8.

12. Toljan, K., Letter to the Editor Regarding the Viewpoint "Evidence of the COVID-19 Virus Targeting the CNS: Tissue Distribution, Host-Virus Interaction, and Proposed Neurotropic Mechanism". ACS Chemical Neuroscience, 2020. 11(8): p. 1192-1194.

13. Sanders, J.M., et al., Pharmacologic Treatments for Coronavirus Disease 2019 (COVID-19): A Review. JAMA, 2020.

14. Arshad, U., et al., Prioritisation of potential anti-SARS-CoV-2 drug repurposing opportunities based on ability to achieve adequate target site concentrations derived from their established human pharmacokinetics. medRxiv, 2020: $p$. 2020.04.16.20068379.

15. Wilson, C.M., 296 - Antiparasitic Agents, in Principles and Practice of Pediatric Infectious Diseases (Fourth Edition), S.S. Long, Editor. 2012, Content Repository Only!: London. p. 1518-1545.e3.

16. DrugBank. Nitazoxanide. 2020 [cited 2020 17/04/2020]; Available from: https://www.drugbank.ca/drugs/DB00507.

17. Keiser, J. and J. Utzinger, Chapter 8 - The Drugs We Have and the Drugs We Need Against Major Helminth Infections, in Advances in Parasitology, X.-N. Zhou, et al., Editors. 2010, Academic Press. p. 197-230.

18. Wang, M., et al., Remdesivir and chloroquine effectively inhibit the recently emerged novel coronavirus (2019-nCoV) in vitro. Cell Research, 2020. 30(3): p. 269-271. 
19. Cao, J., J.C. Forrest, and X. Zhang, A screen of the NIH Clinical Collection small molecule library identifies potential anti-coronavirus drugs. Antiviral Res, 2015. 114: p. 1-10.

20. OpenData Portal. Nitazoxanide. 2020 [10/09/2020]; Available from: https://opendata.ncats.nih.gov/covid19/databrowser?q=Nitazoxanide.

21. Bobrowski, T., et al., Discovery of Synergistic and Antagonistic Drug Combinations against SARS-CoV-2 In Vitro. bioRxiv : the preprint server for biology, 2020: $p$. 2020.06.29.178889.

22. Rossignol, J.F. and Y.M. El-Gohary, Nitazoxanide in the treatment of viral gastroenteritis: a randomized double-blind placebo-controlled clinical trial. Alimentary Pharmacology \& Therapeutics, 2006. 24(10): p. 1423-1430.

23. Korba, B.E., et al., Potential for Hepatitis C Virus Resistance to Nitazoxanide or Tizoxanide. Antimicrobial Agents and Chemotherapy, 2008. 52(11): p. 4069-4071.

24. Korba, B.E., et al., Nitazoxanide, tizoxanide and other thiazolides are potent inhibitors of hepatitis $B$ virus and hepatitis $C$ virus replication. Antiviral Research, 2008. 77(1): p. 56-63.

25. Dang, W., et al., Nitazoxanide Inhibits Human Norovirus Replication and Synergizes with Ribavirin by Activation of Cellular Antiviral Response. Antimicrobial Agents and Chemotherapy, 2018. 62(11): p. e00707-18.

26. Koszalka, P., D. Tilmanis, and A.C. Hurt, Influenza antivirals currently in late-phase clinical trial. Influenza and other respiratory viruses, 2017. 11(3): p. 240-246.

27. Rossignol, J.-F., Nitazoxanide: A first-in-class broad-spectrum antiviral agent. Antiviral Research, 2014. 110: p. 94-103.

28. OpenData Portal. Tizoxanide. 2020 [10/09/2020]; Available from: https://opendata.ncats.nih.gov/covid19/databrowser?q=Tizoxanide.

29. Pizzorno, A., et al., Drug Repurposing Approaches for the Treatment of Influenza Viral Infection: Reviving Old Drugs to Fight Against a Long-Lived Enemy. Frontiers in Immunology, 2019. 10(531).

30. Haffizulla, J., et al., Effect of nitazoxanide in adults and adolescents with acute uncomplicated influenza: a double-blind, randomised, placebo-controlled, phase $2 b / 3$ trial. Lancet Infect Dis, 2014. 14(7): p. 609-18.

31. Rossignol, J.F., Nitazoxanide: a first-in-class broad-spectrum antiviral agent. Antiviral Res, 2014. 110: p. 94-103.

32. Clerici, M., et al., The anti-infective Nitazoxanide shows strong immumodulating effects (155.21). 2011. 186(1 Supplement): p. 155.21-155.21.

33. Miner, K., et al., Drug Repurposing: The Anthelmintics Niclosamide and Nitazoxanide Are Potent TMEM16A Antagonists That Fully Bronchodilate Airways. Frontiers in pharmacology, 2019. 10: p. 51-51.

34. ClinicalTrials.gov. Clinical Trials. 2020 [cited 2020 10/09/2020]; Available from: https://clinicaltrials.gov/.

35. Pepperrell, T., et al., Review of safety and minimum pricing of nitazoxanide for potential treatment of COVID-19. Journal of Virus Eradication, 2020. 6(2): p. 52-60.

36. Stockis, A., et al., Nitazoxanide pharmacokinetics and tolerability in man using single ascending oral doses. International Journal of Clinical Pharmacology and Therapeutics, 2002. 40(5): p. 213-220.

37. Schaefer, I.-M., et al., In situ detection of SARS-CoV-2 in lungs and airways of patients with COVID-19. Modern Pathology, 2020. 
38. Nepogodiev, D., et al., Mortality and pulmonary complications in patients undergoing surgery with perioperative SARS-CoV-2 infection: an international cohort study. The Lancet, 2020. 396(10243): p. 27-38.

39. Zhou, F., et al., Clinical course and risk factors for mortality of adult inpatients with COVID-19 in Wuhan, China: a retrospective cohort study. The Lancet, 2020. 395(10229): p. 1054-1062.

40. Trezza, C.R. and A.D.M. Kashuba, Pharmacokinetics of Antiretrovirals in Genital Secretions and Anatomic Sites of HIV Transmission: Implications for HIV Prevention. Clinical Pharmacokinetics, 2014. 53(7): p. 611-624.

41. Cottrell, M.L., N. Srinivas, and A.D.M. Kashuba, Pharmacokinetics of antiretrovirals in mucosal tissue. Expert Opinion on Drug Metabolism \& Toxicology, 2015. 11(6): p. 893-905.

42. Broliden, K., Innate Molecular and Anatomic Mucosal Barriers against HIV Infection in the Genital Tract of HIV-Exposed Seronegative Individuals. The Journal of Infectious Diseases, 2010. 202(Supplement_3): p. S351-S355.

43. Yao, X., et al., In Vitro Antiviral Activity and Projection of Optimized Dosing Design of Hydroxychloroquine for the Treatment of Severe Acute Respiratory Syndrome Coronavirus 2 (SARS-CoV-2). Clinical Infectious Diseases, 2020.

44. Alexander, S.P.H., et al., A rational roadmap for SARS-CoV-2/COVID-19 pharmacotherapeutic research and development: IUPHAR Review 29. British Journal of Pharmacology. $n / a(n / a)$.

45. Venisse, N., et al., Concerns about pharmacokinetic (PK) and pharmacokineticpharmacodynamic (PK-PD) studies in the new therapeutic area of COVID-19 infection. Antiviral Research, 2020. 181: p. 104866.

46. Rajoli, R.K.R., et al., Physiologically Based Pharmacokinetic Modelling to Inform Development of Intramuscular Long-Acting Nanoformulations for HIV. Clin Pharmacokinet 2015. 54(6): p. 639-650.

47. Rajoli, R.K.R., et al., Predicting Drug-Drug Interactions Between Rifampicin and LongActing Cabotegravir and Rilpivirine Using Physiologically Based Pharmacokinetic Modeling. J Infect Dis, 2019. 219(11): p. 1735-1742.

48. Prevention, C.f.D.C.a. Anthropometric Reference Data for Children and Adults: United States, 2011-2014. 2016 [cited 2019 17/10/2019]; Available from: https://www.cdc.gov/nchs/data/series/sr 03/sr03 039.pdf.

49. Williams, L.R. Reference values for total blood volume and cardiac output in humans. 1994 [cited Access 1994 Accessed: 18/01/2018]; Available from: https://www.osti.gov/biblio/10186900-reference-values-total-blood-volumecardiac-output-humans.

50. Bosgra, S., et al., An improved model to predict physiologically based model parameters and their inter-individual variability from anthropometry. Crit Rev Toxicol, 2012. 42(9): p. 751-767.

51. Yu, L.X. and G.L. Amidon, A compartmental absorption and transit model for estimating oral drug absorption. Int J Pharm, 1999. 186(2): p. 119-125.

52. Peters, S., Evaluation of a Generic Physiologically Based Pharmacokinetic Model for Lineshape Analysis. Clin Pharmacokinet 2008. 47(4): p. 261-275.

53. Rodgers, T., D. Leahy, and M. Rowland, Physiologically Based Pharmacokinetic Modeling 1: Predicting the Tissue Distribution of Moderate-to-Strong Bases. Journal of Pharmaceutical Sciences, 2005. 94(6): p. 1259-1276. 
54. Rodgers, T. and M. Rowland, Physiologically based pharmacokinetic modelling 2: Predicting the tissue distribution of acids, very weak bases, neutrals and zwitterions. Journal of Pharmaceutical Sciences, 2006. 95(6): p. 1238-1257.

55. Sun, D., et al., Comparison of Human Duodenum and Caco-2 Gene Expression Profiles for 12,000 Gene Sequences Tags and Correlation with Permeability of 26 Drugs. Pharmaceutical Research, 2002. 19(10): p. 1400-1416.

56. Gertz, M., et al., Prediction of Human Intestinal First-Pass Metabolism of 25 CYP3A Substrates from In Vitro Clearance and Permeability Data. Drug Metab Dispos 2010. 38(7): p. 1147-1158.

57. Marcellin, F., et al., Determinants of unplanned antiretroviral treatment interruptions among people living with HIV in Yaoundé, Cameroon. Journal of Tropical Medicine and International Health, 2008. 13(12): p. 1470-8.

58. Broekhuysen, J., et al., Nitazoxanide: pharmacokinetics and metabolism in man. International Journal of Clinical Pharmacology and Therapeutics, 2000. 38(8): p. 387394.

59. Belardo, G., et al., Synergistic Effect of Nitazoxanide with Neuraminidase Inhibitors against Influenza A Viruses <em $>$ In Vitro</em>. Antimicrobial Agents and Chemotherapy, 2015. 59(2): p. 1061-1069.

60. Giuseppe Belardo, S.L.F., Orlando Cenciarelli, Stefania Carta, Jean-Francois Rossignol, M. Gabriella Santoro. Nitazoxanide, a Novel Potential Anti-Influenza Drug, Acting in Synergism with Neuraminidase Inhibitors. in IDSA Annual Meeting. 2011. Boston, MA, USA, Available from: https://idsa.confex.com/idsa/2011/webprogram/Paper31075.html.

61. Chenel, M., et al., Drug-drug interaction predictions with PBPK models and optimal multiresponse sampling time designs: application to midazolam and a phase I compound. Part 1: comparison of uniresponse and multiresponse designs using PopDes. Journal of Pharmacokinetics and Pharmacodynamics, 2008. 35(6): p. 635659.

62. Nyberg, J., et al., Methods and software tools for design evaluation in population pharmacokinetics-pharmacodynamics studies. British Journal of Clinical Pharmacology, 2015. 79(1): p. 6-17.

63. Haffizulla, J., et al., Effect of nitazoxanide in adults and adolescents with acute uncomplicated influenza: a double-blind, randomised, placebo-controlled, phase $2 b / 3$ trial. The Lancet Infectious Diseases, 2014. 14(7): p. 609-618.

64. Tilmanis, D., et al., The susceptibility of circulating human influenza viruses to tizoxanide, the active metabolite of nitazoxanide. Antiviral Research, 2017. 147: p. 142-148.

65. McCreary, E.K., J.M. Pogue, and o.b.o.t.S.o.I.D. Pharmacists, Coronavirus Disease 2019 Treatment: A Review of Early and Emerging Options. Open Forum Infectious Diseases, 2020. 7(4).

66. Walls, A.C., et al., Structure, Function, and Antigenicity of the SARS-CoV-2 Spike Glycoprotein. Cell, 2020. 181(2): p. 281-292.e6.

67. Taubenberger, J.K. and D.M. Morens, The pathology of influenza virus infections. Annual review of pathology, 2008. 3: p. 499-522.

68. Ranjbar, S., et al., Cytoplasmic RNA Sensor Pathways and Nitazoxanide Broadly Inhibit Intracellular Mycobacterium tuberculosis Growth. iScience, 2019. 22: p. 299313. 
69. Marta Boffito, D.J.B., Charles Flexner, Peter Sjö, Terrence F. Blaschke, Peter W. Horby, Dario Cattaneo, Edward P Acosta, Peter Anderson, Steven E Kern, Andrew Owen, Towards consensus on correct interpretation of protein binding in plasma and other biological matrices for COVID-19 therapeutic development. Submitted. 2020.

70. Drugs.com. Nitazoxanide. 2020 [cited 2020 18/04/2020]; Available from: https://www.drugs.com/ppa/nitazoxanide.html.

71. Stockis, A., et al., Nitazoxanide pharmacokinetics and tolerability in man using single ascending oral doses. Int J Clin Pharmacol Ther, 2002. 40(5): p. 213-20.

72. Stockis, A., et al., Nitazoxanide pharmacokinetics and tolerability in man during 7 days dosing with $0.5 \mathrm{~g}$ and $1 \mathrm{~g}$ b.i.d. International Journal of Clinical Pharmacology and Therapeutics, 2002. 40(5): p. 221-227.

73. Marcelín-Jiménez, G., et al., Development of a method by UPLC-MS/MS for the quantification of tizoxanide in human plasma and its pharmacokinetic application. Bioanalysis, 2012. 4(8): p. 909-917.

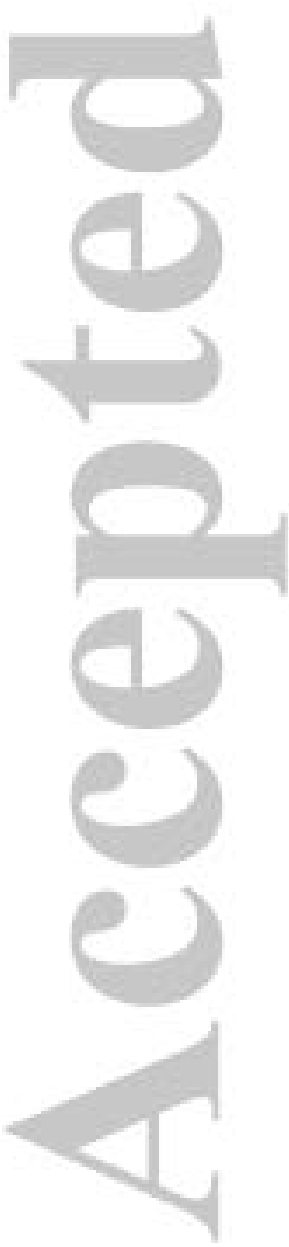



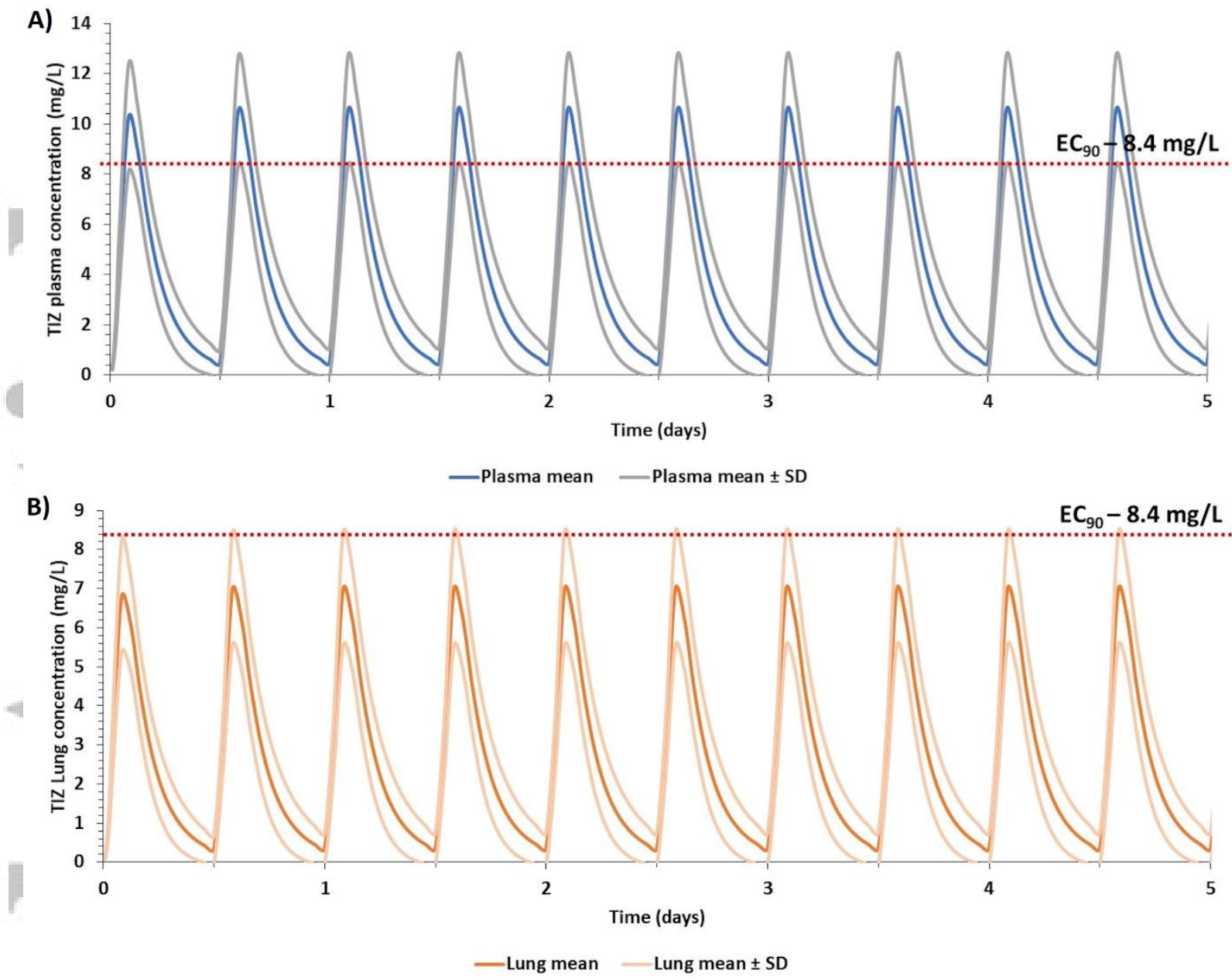

Figure 1 Simulated plasma (a) and lung (b) concentration for nitazoxanide $600 \mathrm{mg}$ BID for 5 days with food relative to the average reported tizoxanide $\mathrm{EC}_{90}$ value for influenza strains (Table S1) similar to those in a previous phase $2 \mathrm{~b} / 3$ trial in uncomplicated influenza [30]. 

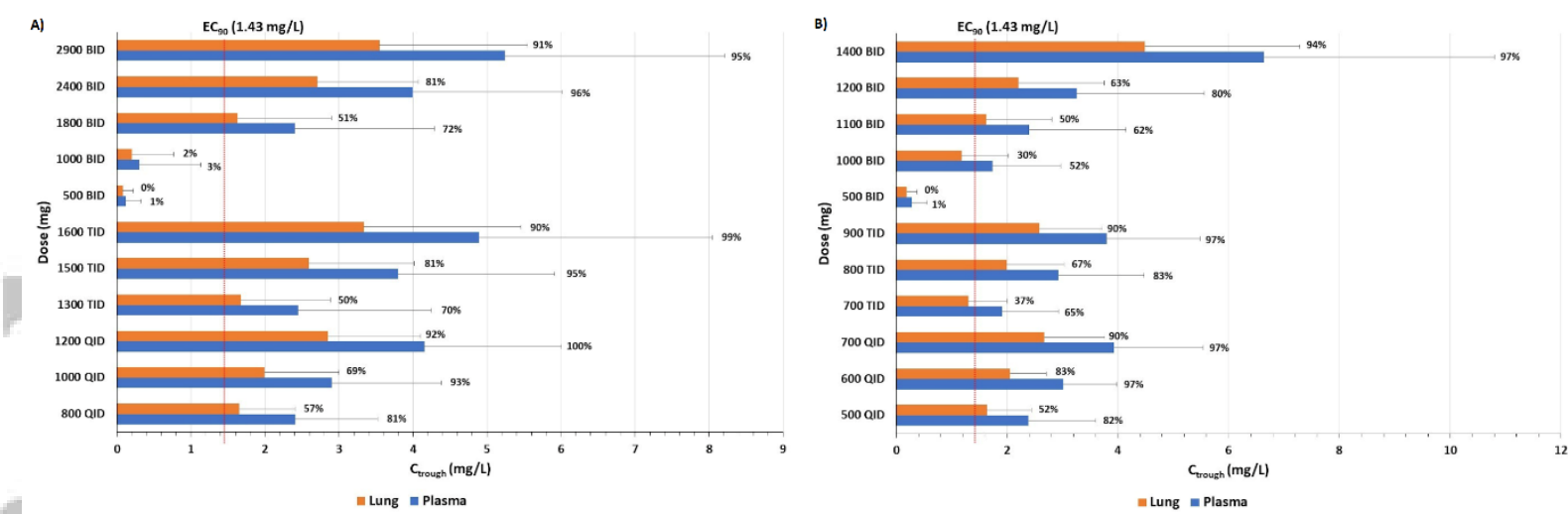

Figure 2. (a) Predicted tizoxanide $C_{\text {trough }}(B I D-12 h$, TID $-8 h$, QID $-6 h$ ) for various dosing regimens of nitazoxanide in fasted state at the end of the first dose. Data are presented as mean and error bars represent standard deviation. The percentages adjacent to the bar chart indicate the percentages of simulated population over $\mathrm{EC}_{90}$ of nitazoxanide for SARSCoV-2. (b) Predicted tizoxanide $C_{\text {trough }}(B I D-12 h$, TID $-8 h$, QID $-6 h$ ) for various dosing regimens of nitazoxanide in fed state at the end of the first dose. Data are presented as mean and error bars represent standard deviation. The percentages adjacent to the bar chart indicate the percentages of simulated population over $\mathrm{EC}_{90}$ of nitazoxanide for SARSCoV-2.

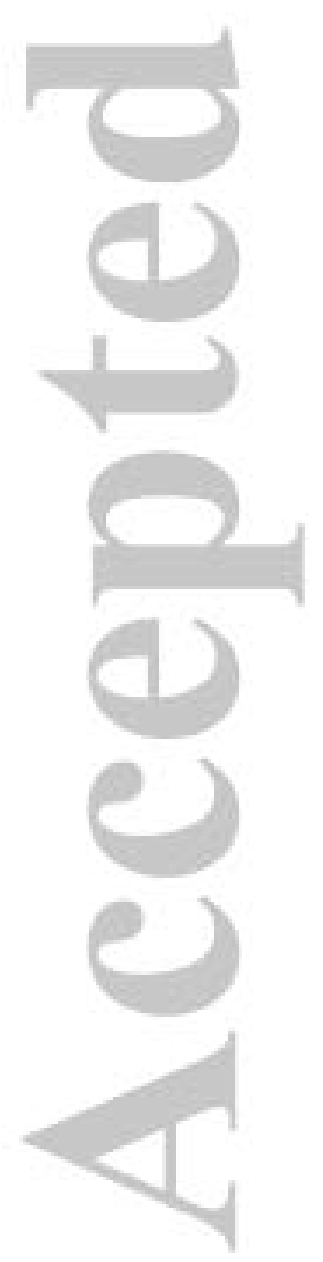



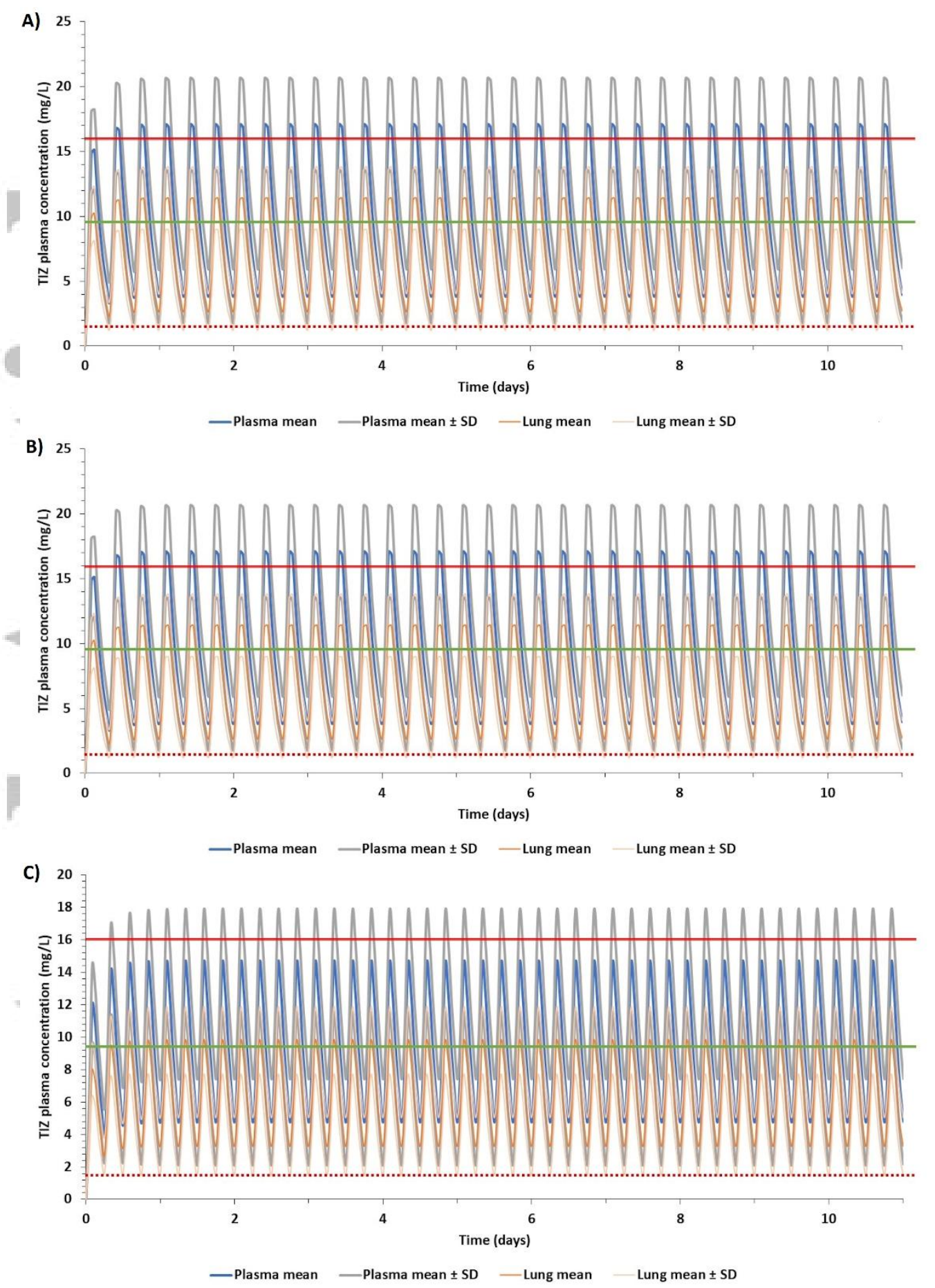

Figure 3 Predicted plasma and lung concentrations for optimal doses during the fed state at different regimens reaching steady state - (a) $1400 \mathrm{mg} \mathrm{BID,} \mathrm{(b)} 900 \mathrm{mg}$ TID and (c) $700 \mathrm{mg}$ QID. TIZ - tizoxanide, SD - standard deviation, solid red line indicates clinical $C_{\max }$ of $1 \mathrm{~g}$ single dose at fed state [36], solid green line represents clinical $C_{\max }$ of $500 \mathrm{mg}$ single dose [72] at fed state and the dotted red line represents the EC $_{90}$ of nitazoxanide for SARS-CoV-2 [18]. 
Table 1 Nitazoxanide input parameters for the PBPK model.

\begin{tabular}{|l|c|c|}
\hline \multicolumn{1}{|c|}{ Parameter } & Nitazoxanide & Tizoxanide \\
\hline Molecular weight & $307.28[15]$ & $>99 \%[53]$ \\
\hline * Protein binding & $>99 \%[15]$ & $3.2[56]$ \\
\hline Log P & $1.63[15]$ & $6.7[57]$ \\
\hline pKa (acidic) & $8.3[15]$ & 0.55 \\
\hline R & 0.55 & $2[56]$ \\
\hline Number of hydrogen bond donors & $1[15]$ & $136[56]$ \\
\hline Polar surface area & $114.11[15]$ & - \\
\hline Apparent permeability (cm/s) & $1.11 \mathrm{e}-4[58]$ & - \\
\hline Apparent clearance (L/h) & - & $38.68 \pm 14.02[55]$ \\
\hline Volume of distribution (L) & - & $1.38 \pm 0.29[55]$ \\
\hline Half-life (h) & $-34 \pm 4.97[55]$ \\
\hline
\end{tabular}

$\mathrm{R}$ - blood to plasma ratio was predicted from Paixão et al. [36] - not available, apparent permeability was assessed in HT29-19A cells and this value was considered the same in caco-2 cells for tizoxanide

${ }^{*}$ Protein binding was considered as $99 \%$ for the PBPK model 
Table 2 Tizoxanide validation against observed data for various single oral doses in the fasted state.

\begin{tabular}{|c|c|c|c|c|}
\hline $\begin{array}{l}\text { Dose } \\
\text { (mg) }\end{array}$ & $\begin{array}{c}\text { Pharmacokinetic } \\
\text { parameter }\end{array}$ & Observed & Simulated & Simulated/observed \\
\hline \multirow[t]{3}{*}{$500[40]$} & ${ }^{*} \mathrm{AUC}_{0-12 \mathrm{~h}}(\mu \mathrm{g} \cdot \mathrm{h} / \mathrm{ml})$ & $27.02 \pm 6.24$ & $24.32 \pm 5.07$ & 0.90 \\
\hline & ${ }^{*} C_{\max }(\mu \mathrm{g} / \mathrm{ml})$ & $6.80 \pm 1.32$ & $6.47 \pm 1.17$ & 0.95 \\
\hline & ${ }^{+} C_{\text {trough }}(\mu \mathrm{g} / \mathrm{ml})$ & 0.106 & $0.119 \pm 0.185$ & 1.12 \\
\hline \multirow{5}{*}{$\begin{array}{l}1000 \\
{[29]}\end{array}$} & ${ }^{\wedge} \mathrm{AUC}_{0-24 \mathrm{~h}}(\mu \mathrm{g} \cdot \mathrm{h} / \mathrm{ml})$ & $50.6(29.0-$ & 48.9 (34.3- & 0.93 \\
\hline & & 88.4) & 63.4) & \\
\hline & ${ }^{\wedge} C_{\max }(\mu \mathrm{g} / \mathrm{ml})$ & $12.3(8.21-$ & $12.9(10.2-$ & 1.05 \\
\hline & & 18.3) & 12.9) & \\
\hline & ${ }^{\dagger} C_{\text {trough }}(\mu \mathrm{g} / \mathrm{ml})$ & 0.23 & $\begin{array}{r}0.21(0.09- \\
0.53)\end{array}$ & 0.93 \\
\hline \multirow{6}{*}{$\begin{array}{l}2000 \\
{[29]}\end{array}$} & ${ }^{\wedge} A \cup C_{0-24 h}(\mu \mathrm{g} \cdot \mathrm{h} / \mathrm{ml})$ & $59.2(36.5-$ & $68.5(48.9-$ & 1.12 \\
\hline & & 95.9) & 84.1) & \\
\hline & ${ }^{\wedge} \mathrm{C}_{\max }(\mu \mathrm{g} / \mathrm{ml})$ & 9.08 (7.07- & $9.45(7.18-$ & 1.04 \\
\hline & & 11.7) & 11.7) & \\
\hline & ${ }^{\wedge \dagger} C_{\text {trough }}(\mu \mathrm{g} / \mathrm{ml})$ & 1.49 & $1.33(0.45-$ & 0.89 \\
\hline & & & 2.21) & \\
\hline \multirow{5}{*}{$\begin{array}{l}3000 \\
{[29]}\end{array}$} & ${ }^{\wedge} \mathrm{AUC}_{0-24 \mathrm{~h}}(\mu \mathrm{g} \cdot \mathrm{h} / \mathrm{ml})$ & $52.9(34.6-$ & 42.6 (31.7- & 0.81 \\
\hline & & 81.0) & $53.6)$ & \\
\hline & ${ }^{\wedge} \mathrm{C}_{\max }(\mu \mathrm{g} / \mathrm{ml})$ & 7.39 (6.07- & 7.51 (5.68- & 1.02 \\
\hline & & 8.98) & 9.33) & \\
\hline & ${ }^{\wedge \dagger} C_{\text {trough }}(\mu \mathrm{g} / \mathrm{ml})$ & 0.6 & $\begin{array}{r}0.93(0.79- \\
1.06)\end{array}$ & 1.54 \\
\hline \multirow{4}{*}{$\begin{array}{l}4000 \\
{[29]}\end{array}$} & ${ }^{\wedge} \mathrm{A} U \mathrm{C}_{0-24 \mathrm{~h}}(\mu \mathrm{g} \cdot \mathrm{h} / \mathrm{ml})$ & $88.5(53.5-146)$ & $76.9(60.1-$ & 0.87 \\
\hline & & & 93.8) & \\
\hline & ${ }^{\wedge} \mathrm{C}_{\max }(\mu \mathrm{g} / \mathrm{ml})$ & $10.5(8.16-$ & $9.58(7.34-$ & 0.91 \\
\hline & & 13.5) & 11.8) & \\
\hline
\end{tabular}




\begin{tabular}{|r|l|r|r|r|}
\hline & ${ }^{\wedge \dagger} C_{\text {trough }}(\mu \mathrm{g} / \mathrm{ml})$ & 2.48 & $2.44(2.19-$ & 0.98 \\
& & & $2.67)$ & \\
\hline
\end{tabular}

${ }^{*} C_{\max }$ and $A \cup C_{0-12 h}$ are represented as arithmetic mean $\pm S D,{ }^{\wedge} C_{\max }$ and $A U C_{0-24 h}$ are represented as geometric mean (mean - SD, mean $+S D$ ), ${ }^{+} C_{\text {trough }}$ is $C_{12}$ and has been digitised from the pharmacokinetic curve as the geometric mean is not available, arithmetic mean is shown for observed and arithmetic mean (mean -SD, mean $+S D$ ) are shown for simulated data, ${ }^{\wedge} C_{\max }, A \cup C_{0-24 h}$ and ${ }^{\wedge} C_{\text {trough }}$ were normalised to a $1000 \mathrm{mg}$ dose.

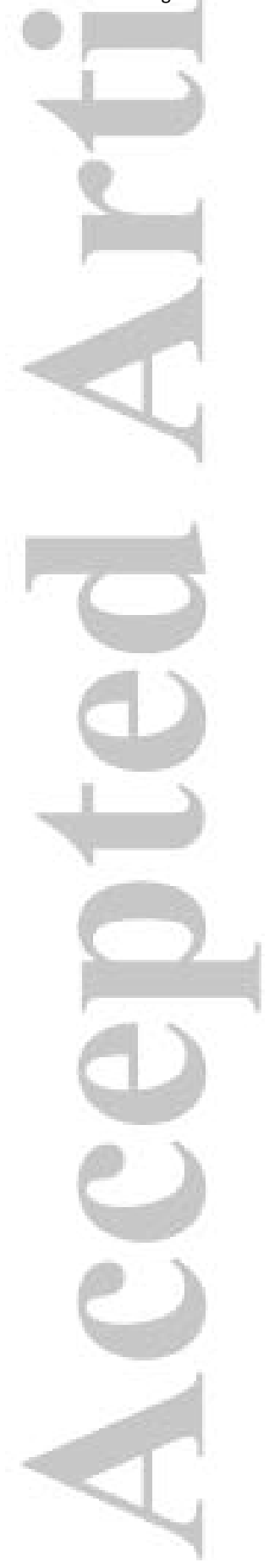


Table 3 Tizoxanide validation against observed data for various single and multiple oral doses when given with food.

\begin{tabular}{|c|c|c|c|c|}
\hline \begin{tabular}{|l|} 
Dose \\
(mg)
\end{tabular} & $\begin{array}{c}\text { Pharmacokinetic } \\
\text { parameter }\end{array}$ & Observed & Simulated & Simulated/observed \\
\hline \multirow{3}{*}{$\begin{array}{l}500 \\
\text { (single) } \\
{[54]}\end{array}$} & ${ }^{*} A \cup C_{0 \text {-last }}(\mu \mathrm{g} \cdot \mathrm{h} / \mathrm{ml})$ & $\begin{array}{r}41.8(36.1- \\
48.4)\end{array}$ & $\begin{array}{r}33.2(23.1- \\
43.2)\end{array}$ & 0.79 \\
\hline & $\mathrm{C}_{\max }(\mu \mathrm{g} / \mathrm{ml})$ & $\begin{array}{r}10.4(8.65- \\
12.6)\end{array}$ & $\begin{array}{r}8.08(6.17- \\
9.98)\end{array}$ & 0.78 \\
\hline & ${ }^{\dagger} C_{\text {trough }}(\mu \mathrm{g} / \mathrm{ml})$ & 0.178 & $0.28(0-0.5)$ & 1.56 \\
\hline \multirow{3}{*}{$\begin{array}{l}500 \text { BID } \\
\text { (multiple) } \\
{[54]}\end{array}$} & $\begin{array}{l}{ }^{*} \mathrm{AUC}_{0-12 \mathrm{~h}} \\
(\mu \mathrm{g} . \mathrm{h} / \mathrm{ml})\end{array}$ & $\begin{array}{r}48.7(36.0- \\
65.9)\end{array}$ & $\begin{array}{r}32.8(19.5- \\
46.1)\end{array}$ & 0.67 \\
\hline & $\mathrm{C}_{\max }(\mu \mathrm{g} / \mathrm{ml})$ & $\begin{array}{r}9.05(7.13- \\
11.5)\end{array}$ & $\begin{array}{r}7.66(5.89- \\
9.44)\end{array}$ & 0.85 \\
\hline & ${ }^{\dagger} C_{\text {trough }}(\mu \mathrm{g} / \mathrm{ml})$ & 0.310 & $0.35(0-0.89)$ & 1.11 \\
\hline \multirow{3}{*}{$\begin{array}{l}1000 \\
\text { (single) } \\
{[54]} \\
\end{array}$} & ${ }^{*} A \cup C_{0 \text {-last }}(\mu \mathrm{g} \cdot \mathrm{h} / \mathrm{ml})$ & $85.9(68.8-107)$ & $\begin{array}{r}91.3(69- \\
113.5)\end{array}$ & 1.06 \\
\hline & $C_{\max }(\mu \mathrm{g} / \mathrm{ml})$ & $\begin{array}{r}14.4(10.8- \\
19.2)\end{array}$ & $\begin{array}{r}17.8(14.3- \\
21.3)\end{array}$ & 1.23 \\
\hline & ${ }^{\dagger} C_{\text {trough }}(\mu \mathrm{g} / \mathrm{ml})$ & 0.786 & $1.43(0.2-2.22)$ & 1.82 \\
\hline \multirow{3}{*}{$\begin{array}{l}1000 \text { BID } \\
\text { (multiple) } \\
{[54]}\end{array}$} & $\begin{array}{l}{ }^{*} \mathrm{AUC}_{0-12 \mathrm{~h}} \\
(\mu \mathrm{g} . \mathrm{h} / \mathrm{ml})\end{array}$ & $144(105-198)$ & $\begin{array}{r}90.9(69- \\
112.8)\end{array}$ & 0.63 \\
\hline & $\mathrm{C}_{\max }(\mu \mathrm{g} / \mathrm{ml})$ & $\begin{array}{r}24.2(20.3- \\
28.7)\end{array}$ & $\begin{array}{r}18.2(14.4- \\
21.9)\end{array}$ & 0.75 \\
\hline & ${ }^{\dagger} C_{\text {trough }}(\mu \mathrm{g} / \mathrm{ml})$ & 1.68 & $\begin{array}{r}1.38(0.33- \\
2.07)\end{array}$ & 0.82 \\
\hline $\begin{array}{l}2000 \\
\text { (single) }\end{array}$ & $\begin{array}{l}{ }^{\wedge} \mathrm{AUC}_{0-24 \mathrm{~h}} \\
(\mu \mathrm{g} \cdot \mathrm{h} / \mathrm{ml})\end{array}$ & $110(88.0-139)$ & $109(74.8-142)$ & 0.99 \\
\hline [29] & ${ }^{\wedge} C_{\max }(\mu \mathrm{g} / \mathrm{ml})$ & $\begin{array}{r}15.8(13.0- \\
19.2)\end{array}$ & $\begin{array}{r}14.3(11.2- \\
17.4)\end{array}$ & 0.91 \\
\hline
\end{tabular}




\begin{tabular}{|c|c|c|c|c|}
\hline & ${ }^{\wedge \dagger} \mathrm{C}_{\text {trough }}(\mu \mathrm{g} / \mathrm{ml})$ & 1.52 & $\begin{array}{r}3.27(1.73- \\
4.46)\end{array}$ & 2.15 \\
\hline $\begin{array}{l}3000 \\
\text { (single) }\end{array}$ & $\begin{array}{l}{ }^{\wedge} \mathrm{AUUC} \mathrm{C}_{0-24 \mathrm{~h}} \\
(\mu \mathrm{g} \cdot \mathrm{h} / \mathrm{ml})\end{array}$ & $95.3(60.0-152)$ & 90 (60.9-119) & 0.94 \\
\hline [29] & ${ }^{\wedge} \mathrm{C}_{\max }(\mu \mathrm{g} / \mathrm{ml})$ & $\begin{array}{r}10.0(7.40- \\
13.5)\end{array}$ & $\begin{array}{r}10.4(8.09- \\
12.7)\end{array}$ & 1.04 \\
\hline & ${ }^{\wedge \dagger} C_{\text {trough }}(\mu \mathrm{g} / \mathrm{ml})$ & 2.35 & $\begin{array}{r}2.64(1.44- \\
3.56)\end{array}$ & 1.12 \\
\hline $\begin{array}{l}4000 \\
\text { (single) }\end{array}$ & $\begin{array}{l}{ }^{\wedge} \mathrm{A} \cup \mathrm{C}_{0-24 \mathrm{~h}} \\
(\mu \mathrm{g} \cdot \mathrm{h} / \mathrm{ml})\end{array}$ & 192 (99.5-370) & $161(125-196)$ & 0.84 \\
\hline [29] & ${ }^{\wedge} C_{\max }(\mu \mathrm{g} / \mathrm{ml})$ & $\begin{array}{r}17.5(11.5- \\
26.5)\end{array}$ & $\begin{array}{r}14.2(11.2- \\
17.2)\end{array}$ & 0.81 \\
\hline & ${ }^{\wedge \dagger} C_{\text {trough }}(\mu \mathrm{g} / \mathrm{ml})$ & 6.55 & $\begin{array}{r}6.52(5.04- \\
7.84)\end{array}$ & 0.99 \\
\hline
\end{tabular}

${ }^{\wedge} C_{\max }$ and $A \cup C$ are represented as geometric mean (mean -SD, mean $+S D$ ) and ${ }^{\wedge} C_{\max }$ and $A U C_{0-24 h}$ were normalised to a $1000 \mathrm{mg}$ dose, ${ }^{\wedge} \mathrm{C}_{\max }$ and $\mathrm{AUC}_{0-24 \mathrm{~h}}$ were normalised to a $1000 \mathrm{mg}$ dose, ${ }^{*} \mathrm{AUC}$ is represented as $A \cup C_{0-\infty}$ after the first dose for single and $A U C_{0-12}$ on day $7,{ }^{\dagger} C_{\text {trough }}$ is $C_{12}$ has been digitised from the pharmacokinetic curve as the geometric mean is not available, arithmetic mean is shown for observed and arithmetic mean (mean - SD, mean + SD) are shown for simulated data 